\title{
COVID-19 pandemic: a health challenge for commoners during the first unlock phase in India
}

\author{
Bijay Halder $^{1}$ (D) Jatisankar Bandyopadhyay ${ }^{1,2}$ (D) Papiya Banik ${ }^{3}$
}

Received: 23 July 2020 / Accepted: 4 March 2021 / Published online: 20 March 2021

(C) The Author(s), under exclusive licence to Springer-Verlag GmbH Germany, part of Springer Nature 2021

\begin{abstract}
Aim COVID-19, the disease caused by the novel coronavirus, is now a worldwide pandemic. This disease has become a reason for disturbance and concern. India, as a densely populated country, took initiative after the pandemic was declared. The objective of this study was to determine the mortality and recovery rates at 30 days from the first unlock phase after five phases of lockdown. The the number of infected people has continually increased, and currently, this pandemic continues to present challenges to public health.

Subject and methods Statistical analysis was used to calculate the mortality rate, ratio between active and death cases, active cases and recovered cases, recovered and death cases in India during the first 30 days of the unlock phase.

Results The relationship between the new cases, deaths and recovered cases, shows that the new and recovered cases increased progressively. From the scatter plot of daily deaths and new cases, the $\mathrm{R}^{2}$ value is 0.0047 . That means the death ratio is low against the new cases. Also, if we look at another scatter plot, the ratio between new cases and recovery rate shows the $\mathrm{R}^{2}$ value is 0.8015 . That means the recovery rate was very high during the study period in India. The $\mathrm{R}^{2}$ value of daily recovery and death is 0.0072. India faced a huge number of new coronavirus cases and increased death rate every day during the first unlock phase. Conclusion There was not the same condition as in the preliminary stage. The affected graphs progressively increased, and the government is fighting to control this deadly infection. Central and state governments are working together to combat this pandemic.
\end{abstract}

Keywords COVID-19 pandemic $\cdot$ Public health $\cdot$ Increases new cases and death $\cdot$ First unlock phase $\cdot$ India

\section{Introduction}

Pandemics lead to serious health-related concerns for people, and the current pandemic is harming the socio-economic condition of every infected country and adversely affecting public health. As implied in the name COVID-19, 'CO' stands for 'corona', 'VI' stands for 'virus', 'D' means 'disease' and '19' represents the year of its first occurrence (Chakraborty and Maity 2020). In June 2020, worldwide 9,129,146 confirmed

Bijay Halder

halder06bijay@gmail.com

1 Department of Remote Sensing and GIS, Vidyasagar University, Midnapore, India

2 Centre for Environmental Studies, Vidyasagar University, Midnapore, India

3 Department of Geography, Calcutta University, Kolkata, India cases and 473,797 deaths were registered by the World Health Organisation (WHO, 24th June 2020 on 4:44 pm CEST). After the COVID-19 outbreak in Wuhan, China, it created a massive loss of life in other countries, including Italy, Iran, France and Spain. There is currently no medicine or treatment to use in defence against this virus; all the affected countries have attempted national lockdown, rapid testing and quarantines (Hamzelou 2020). The epicentre is currently situated in the United States of America (USA). Over 2,295,272 confirmed cases and 120,171 deaths were registered by 24 June 2020 (WHO report, 2020).

In between 2002 and 2003, SARS infected approximately 8000 people and 774 people died. In 2012, WHO registered 2494 people infected and 858 killed by another coronavirus called MERS-CoV (Middle East Respiratory SyndromeCoronavirus), which spread to approximately 27 countries (WHO report 2003, 2013). Coronaviruses are a group of related RNA viruses, and this disease is created in mammals and birds. In the case of the human body, COVID-19 symptoms 
are sometimes similar to the common cold, chest pain and many more. Scientists have divided the virus into four groups, including alpha, beta, gamma and delta. The four common are 229E (alpha), NL63 (Alpha), OC 43 (Beta) and HKU1 (Beta) (Strains of Coronavirus Webmd 2020). However, the SARSlike bat $\mathrm{CoV}$ was transmitted to the human body after having evolved in the Himalayan palm-civet (Song et al. 2005). In the past decades, the world has faced five types of pandemics: H1N1 in 2009, Polio in 2014, Ebola (West Africa) in 2014, Zika in 2016 and Ebola (Democratic Republic Congo) in 2019. WHO registered the sixth worldwide pandemic on 30 January 2020 named COVID-19. The worldwide rates of fatalities and infections have contributed to a huge amount of economic losses recently (Allocati et al. 2016; Fan et al. 2019). This deadly disease has affected the world economically, hampering people's lifestyles. After a few months, there was not yet a vaccine for this virus. Many countries tried to improve the methodology to control the disease and sought a vaccine for the coronavirus but, as of June 2020, were not yet successful. (However, now, several vaccines have been developed in various countries and are being distriubuted, albeit sometimes slowly.) Rapid testing, quarantine and social distancing are used to slow down the social and viral movement, sometimes with unfortunate economic consequences.

Subsequently, this pandemic has affected the world public health and challenged health facilities worldwide. The term novel coronavirus indicates a 'new pathogen of a previous know type' of the virus. The acute disease originated in Wuhan, China, in December 2019. After that, the virus spread throughout China. Then the disease began to affect the other countries of the world, including India. On 30 January, India reported its first case of COVID-19 or novel coronavirus. By 3 February 2020, three cases were registered; all were students who had just come from Wuhan. On 4 March 2020, 22 new cases came to light, where Italian tourists were included (14 infected). The first death due to COVID-19 occurred on 12 March 2020. A 76-year-old man died in Karnataka, State of India. The following day, a 60-year-old woman died in Delhi.
Table 2 Maximum coronavirus infected countries on 24 June 2020

Country name Total cases Total death Total recovered Active cases

\begin{tabular}{lllll}
\hline USA & $2,462,708$ & 124,282 & $1,040,608$ & $1,297,818$ \\
Brazil & $1,192,474$ & 53,874 & 649,908 & 488,692 \\
Russia & 613,994 & 8605 & 375,164 & 230,225 \\
India & 474,272 & 14,914 & 271,934 & 187,424 \\
UK & 306,862 & 43,081 & 0 & 0 \\
Spain & 294,166 & 28,327 & 0 & 0 \\
Peru & 264,689 & 8586 & 151,589 & 104,514 \\
Chile & 254,416 & 4731 & 215,093 & 34,592 \\
Italy & 239,410 & 34,644 & 186,111 & 18,655 \\
Iran & 212,501 & 9996 & 172,096 & 30,409 \\
\hline
\end{tabular}

Data Source: Worldometer, 24 June 2020

Two days later, two more cases were confirmed and both of them had returned from abroad. On the other side, the active cases were increasing gradually. By 17 February, the case number increased by three and by $20 \mathrm{Feb}$, five confirmed death cases were registered all over India. The Government of India decided to protect people from this viral disease and took actions such as implementing the 'Janta Curfew' on 22 March from 7 A.M to 9 P.M and declared the 1st phase of Lockdown from 23 March to 14 April 2020. During lockdown, the main focus of the Government was not only to recover the infected persons but also to control the spread of COVID-19. The Government of India wanted to control the virus in the 1st stage, before it reached the stage of community spreading. In a highly populated country, it is not possible to control the spread of disease when people do not understand the current problem. The lockdown phase was increased gradually but the infected number also increased side by side. In the fourth stage, every day almost 5000 cases were registered and the deaths amounted to approximately 120 per day.

In India, during the fifth phase of lockdown, the coronavirus spread was somewhat limited. However, after 31 May 2020, the government announced that some COVID
Table 1 Maximum coronavirus infected countries on 26 May 2020

\begin{tabular}{lllll}
\hline Country name & Total cases & Total deaths & Total recovered & Actives cases \\
\hline USA & $1,706,277$ & 99,807 & 464,727 & $1,141,743$ \\
Brazil & 376,669 & 23,522 & 153,833 & 199,314 \\
Russia & 362,342 & 3807 & 131,129 & 227,406 \\
Spain & 282,480 & 26,837 & 196,958 & 58,685 \\
UK & 261,184 & 36,914 & 0 & 0 \\
Italy & 230,158 & 32,877 & 141,981 & 55,300 \\
France & 182,942 & 28,432 & 65,199 & 89,311 \\
Germany & 180,808 & 8432 & 162,000 & 10,376 \\
Turkey & 157,814 & 4369 & 120,015 & 33,430 \\
India & 146,376 & 4187 & 61,151 & 81,038 \\
\hline
\end{tabular}

Data Source: Worldometer, 26 May 2020 
Fig. 1 Maximum coronavirus infected countries on 26

May 2020. India is situated in the tenth position of the world's most affected countries

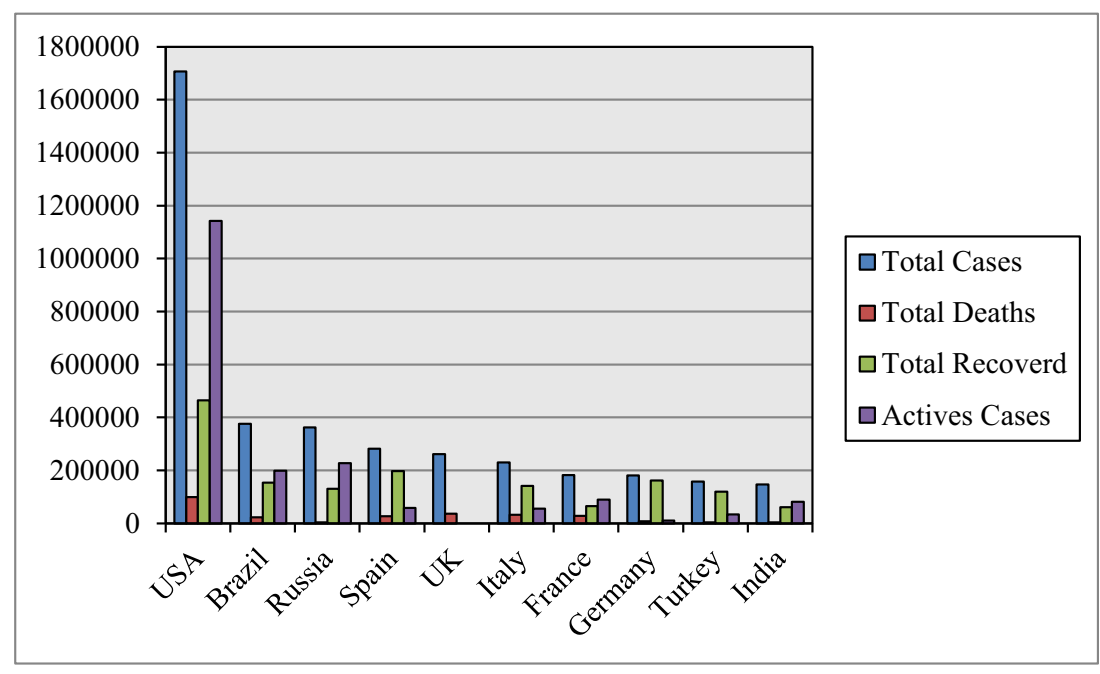

free areas (Green Zone) are concession for goods, malls, religious places, some industry and many more. In every 1 lakh $(100,000)$ population, on world average every 77.6 person was infected. Although, in the USA, 542 persons and, in Germany, 217 people in 1 lakh were infected. In India, only 12.6 people were infected with COVID 19. The recovery frequency was $7.10 \%$ in the month of March that improved to $42.6 \%$ in May, while India's mortality was $2.8 \%$ and the world's mortality rate was $6.15 \%$. The per lakh mortality in India was $0.3 \%$, while the global average was at $4.7 \%$, the USA was at $31.6 \%$ and Germany at $10.2 \%$ (Republicworld.com 31 May 2020). However, the situation of the COVID-19 pandemic in India was very difficult after 1 June 2020. On 25 May, India was situated in 10th position of the worldwide cases, but after one month (24 June 2020), India increased the rank and was situated in 4 th position for coronavirus cases (Worldometer 2020).

\section{Methods}

In this study, the World Health Organization (WHO), Worldometer website data were used to measure the coronavirus situation in India. That website and also the WHO provided the current COVID-19 data on the country-wise situations to help the global community and health organizations to take better sustainable decisions on the current pandemic. The 30 days data were retrieved from the WHO website and used to investigate the effect of COVID-19 during the 'Unlock Phase' in India,

This study included information regarding the situation of India during the first 30 days of the unlock phase, namely the total cases, active cases, deaths and recovered cases of COVID-19 in India. The statistical data was analysed to understand the unlock phase condition of coronavirus in India. The relation between daily death and daily recovery, daily recovery and new cases, daily death and daily new case shows the actual condition during the first unlock phase in India.
Fig. 2 Maximum coronavirus infected countries on 24 June 2020. India is situated in the fourth position of the world's most affected countries

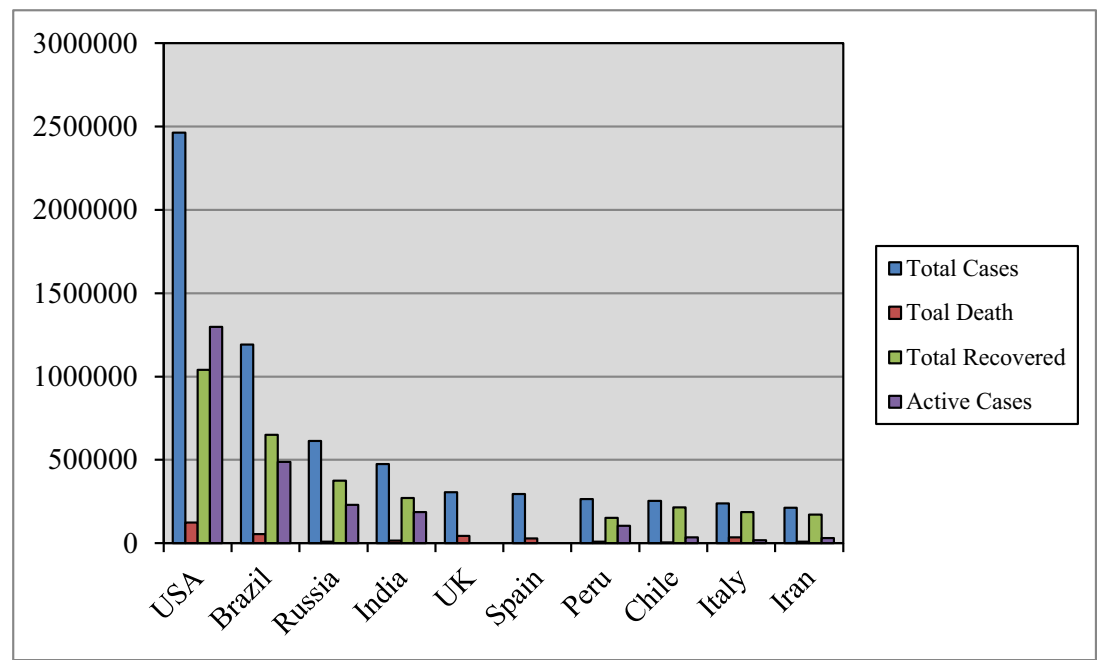


Table 3 Infected condition during unlock phase 1 in India

\begin{tabular}{|c|c|c|c|c|c|}
\hline Date & New cases & New case increases & Death & New death increases & Recovery \\
\hline $01-06-2020$ & 8392 & 0 & 230 & 0 & 3902 \\
\hline 02-06-2020 & 8171 & -221 & 204 & -26 & 4531 \\
\hline 03-06-2020 & 8909 & 738 & 217 & 13 & 3786 \\
\hline 04-06-2020 & 9304 & 395 & 260 & 43 & 4379 \\
\hline 05-06-2020 & 9851 & 547 & 273 & 13 & 4783 \\
\hline $06-06-2020$ & 9887 & 36 & 294 & 21 & 5762 \\
\hline $07-06-2020$ & 9971 & 84 & 287 & -7 & 5153 \\
\hline $08-06-2020$ & 9983 & 12 & 206 & -81 & 5247 \\
\hline $09-06-2020$ & 9987 & 4 & 331 & 125 & 5070 \\
\hline $10-06-2020$ & 9985 & -2 & 279 & -52 & 6814 \\
\hline $11-06-2020$ & 9996 & 11 & 357 & 78 & 5993 \\
\hline $12-06-2020$ & 10,956 & 960 & 396 & 39 & 7259 \\
\hline $13-06-2020$ & 11,458 & 512 & 386 & -10 & 8095 \\
\hline $14-06-2020$ & 11,929 & 471 & 311 & -75 & 7363 \\
\hline $15-06-2020$ & 11,502 & -427 & 325 & 14 & 10,631 \\
\hline $16-06-2020$ & 10,667 & -835 & 380 & 55 & 7232 \\
\hline $17-06-2020$ & 10,974 & 307 & 2003 & 1623 & 6886 \\
\hline $18-06-2020$ & 12,881 & 1907 & 334 & -1669 & 10,744 \\
\hline $19-06-2020$ & 13,586 & 705 & 336 & 2 & 9024 \\
\hline $20-06-2020$ & 14,516 & 930 & 375 & 39 & 13,975 \\
\hline $21-06-2020$ & 15,413 & 897 & 306 & -69 & 9071 \\
\hline $22-06-2020$ & 14,821 & -592 & 445 & 139 & 10,885 \\
\hline $23-06-2020$ & 14,933 & 112 & 312 & -133 & 10,437 \\
\hline $24-06-2020$ & 15,968 & 1035 & 465 & 153 & 13,114 \\
\hline $25-06-2020$ & 16,922 & 954 & 418 & -47 & 13,983 \\
\hline $26-06-2020$ & 17,296 & 374 & 407 & -11 & 10,246 \\
\hline $27-06-2020$ & 18,552 & 1256 & 384 & -23 & 14,229 \\
\hline $28-06-2020$ & 19,906 & 1354 & 410 & 26 & 11,628 \\
\hline $29-06-2020$ & 19,459 & -447 & 380 & -30 & 13,497 \\
\hline $30-06-2020$ & 18,522 & -937 & 418 & 38 & 12,565 \\
\hline Total & 384,697 & & 11,729 & & 256,284 \\
\hline
\end{tabular}

Data Source: World Health Organization (WHO), 24 June 2020

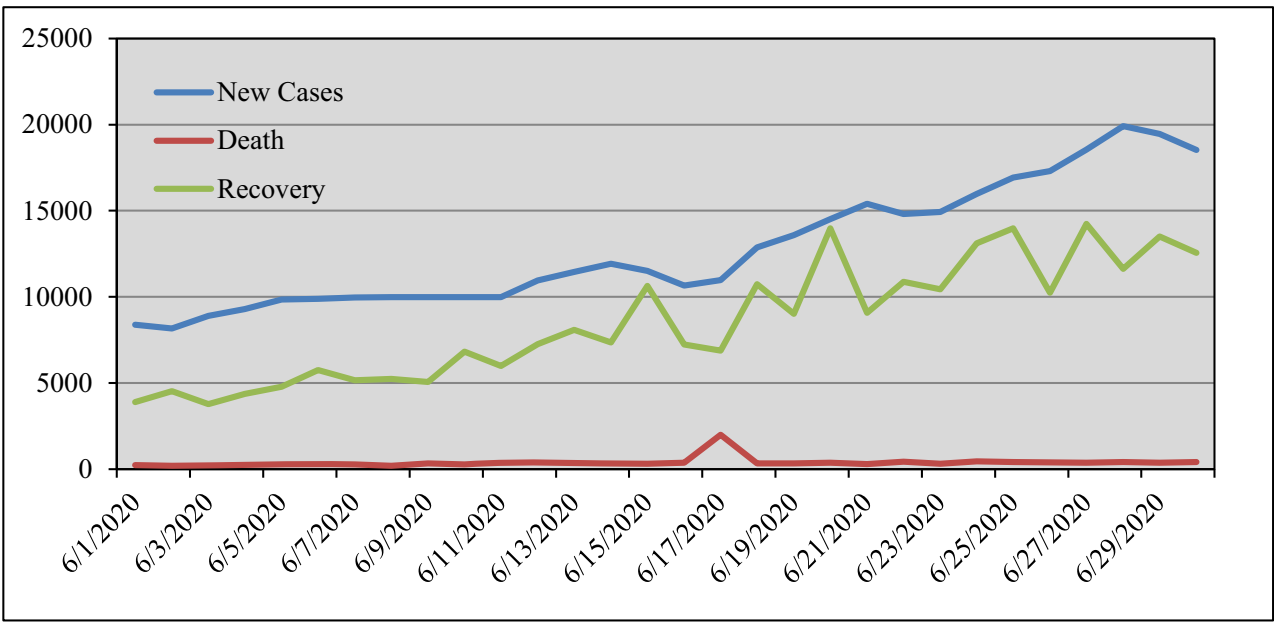

Fig. 3 Relationship between daily new cases, death and recovery in India during the unlock phase 
Fig. 4 Scatter plot shows the relationship between new cases and death

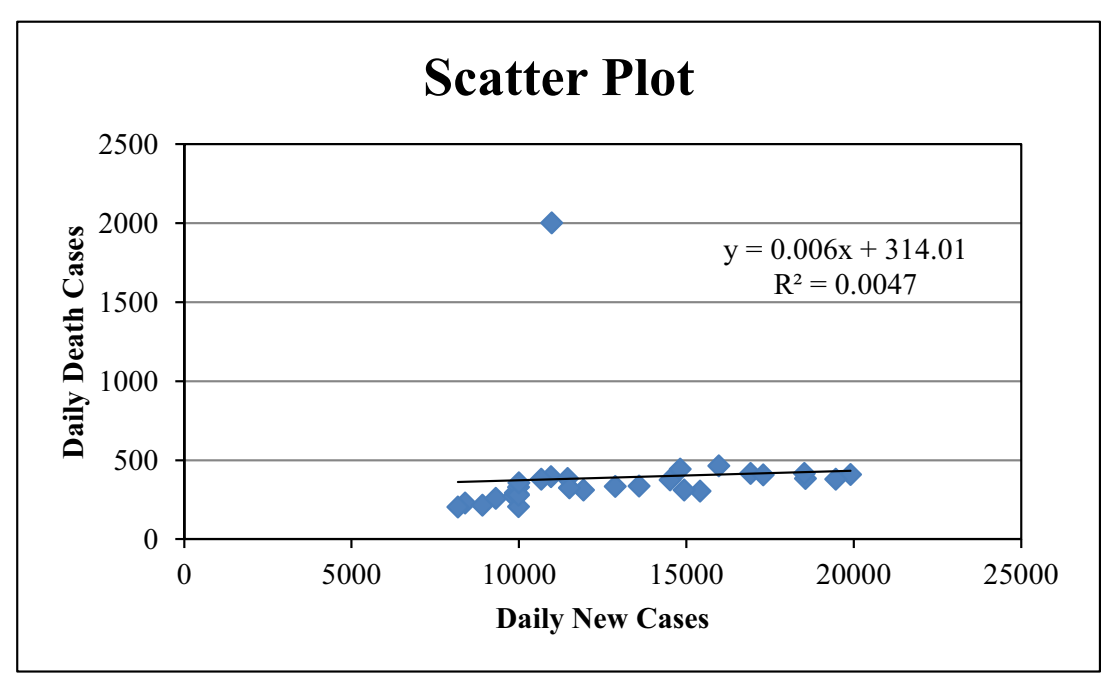

\section{Result and discussion}

India - one of the most densely populated countries in the world - is also trying to protect people from this disaster and save the coronavirus affected patients. According to the details, the death ratio was higher than the last three phases of lockdown. Per day more than 100 people were losing their life; 476,565 patients had recovered from COVID-19 infection; more than $55 \%$ of patients beat acute disease cases. Also, the trend line presents this same scenario. The coronavirus was first discovered or reported in India on 30 January 2020. In the first few days, the active cases were not too high. From this trend line, it is very clear to find that the active cases increased gradually. Also, the recovery ratio is increased, with more than $55 \%$ of patients having already recovered. However, in last 30 days, the new cases and death were very high during unlock phase 1, but the recovered cases were also high during that time.

\section{Coronavirus status in the last one month for most infected ten countries}

The first case of COVID-19 was registered in China, but soon after, the virus spread worldwide, gradually infecting other countries and becoming a pandemic (Worldometer 2020). The USA is the most affected country and the total cases were $2,462,708$ and overall 124,282 persons were killed by this virus as of 26 May 2020 (Fig. 1). During the coronavirus pandemic, the world health condition deteriorated (Table 1). In India, a huge number of people were infected with COVID19. On 26 May, 146,376 cases and 1426 deaths were registered (Worldometer 2020). However, one month later in June, the situation was very bad in India; 474,272 persons were affected by this virus and approximately 14,914 persons had died (Fig. 2). Worldwide, a huge number of people were affected due to this pandemic, including in the USA, Brazil, Russia, India, Spain, UK, Peru, Chile, Italy and Iran (Table 2).

\section{COVID-19 situation during first $\mathbf{3 0}$ days of the unlock phase in India}

In India, the spread of the novel coronavirus was divided into phases. From 30 January 2020 until 31 May 2020, the lockdown is divided into 5 phases. From 30 January 2020 to 22 March 2020 is considered as the before lockdown phase. On 30 January 2020, a case in Karnataka was registered, then the second case was registered on 2 February 2020 in Delhi, the third on 3 February 2020 and the fourth one was registered almost a month later, on 2 March 2020. Also, the first death case came out on 13 March 2020 from Karnataka and the second death was reported from Delhi on 14 March 2020. On 17 March, the third case was registered. There were only a total of 5 death cases before the lockdown phase, and there were 341 confirmed cases. After 'Janta Curfew' was implemented on 22 March as of $14 \mathrm{~h}$, the Govt. of India decided to lockdown the country from 23 March (5:00 pm) to 14 April, which isconsidered as the lockdown phase. In the first five days, the average of confirmed cases was approximately 76.6 people, whereas in the last five days of phase 1 lockdown, it was 899.6 people. Also, the average number of deaths for the first five days was 2.4 people, and in the last five days, it increased to 34 .

After the lockdown was over, the government initiated an unlock phase 1 for handling this pandemic. Some restrictions were applied by the government, but private offices, some parts of government offices, small industries, religious places, shopping malls, restaurants and food markets were open for public use. However, social distancing remains the main way to stay healthy. As a densely populated country, India faces many challenges during this pandemic, and in some places, 
Fig. 5 Scatter plot shows the relationship between new cases and recovery

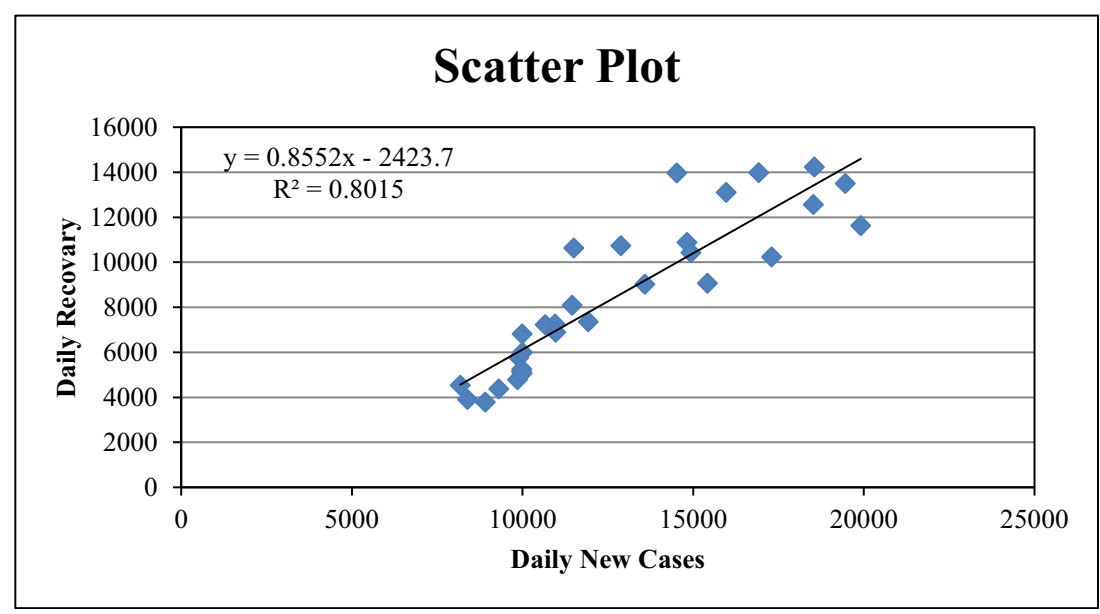

people are not maintaining their social distancing from other people. The Government has taken some valuable steps for controlling the virus. However, in a developing country, it is a big challenge for common people to earn their daily food.

In India, during the first unlock phase, a total of 384,697 new cases were registered within 30 days, and within 122 days, a total of 200,547 cases were registered. Overall, $65.73 \%$ new cases were registered within 30 days. The new cases gradually increased in India. Side by side, death and recovered cases also increased; $62.43 \%$ death rate and $66.07 \%$ recovery rate were shown in the worldometer data. During the unlock phase of 1 June to 30 June, the lowest number of new cases was 8171 and the highest number of cases was 19,906 people infected (Table 3).

In the relationship between the new cases, deaths and recovered cases, shows that the new cases and the recovered cases increased gradually (Fig. 3). In the scatter plot of daily death and daily new cases, the $\mathrm{R}^{2}$ value is 0.0047 (Fig. 4). Also, if we look at another scatter plot, the ratio between new cases and recovery rate shows an $R^{2}$ value of 0.8015 (Fig. 5). That means the recovery rate was very high during that time in India. In addition, the daily recovery and daily death's $\mathrm{R}^{2}$ value is 0.0072 (Fig. 6). That means the death ratio is low against the new cases.

\section{Conclusion}

India is currently a developing country, with many projects underway. India has 1.21 billion people and a population density of 382 per sq. km (Census of India, 2011). This huge population presents challenges to containing the spread of the coronavirus. The Government of India took initial steps to combat the COVID-19 pandemic. This study estimated the COVID-19 condition on a global basis and particularly in the context of India. The novel coronavirus started in Wuhan, China, in December 2019. By June 2020, the virus had spread over 216 countries (WHO report 2020). As of June 2020, the USA, Spain, France, Russia, Italy and India were the most affected nations worldwide, and there were no drugs to shield against the pandemic. Many countries revealed weaknesses in their health capability, and some countries managed a positive report from the pandemic.
Fig. 6 Scatter plot shows the relationship between daily death and recovery

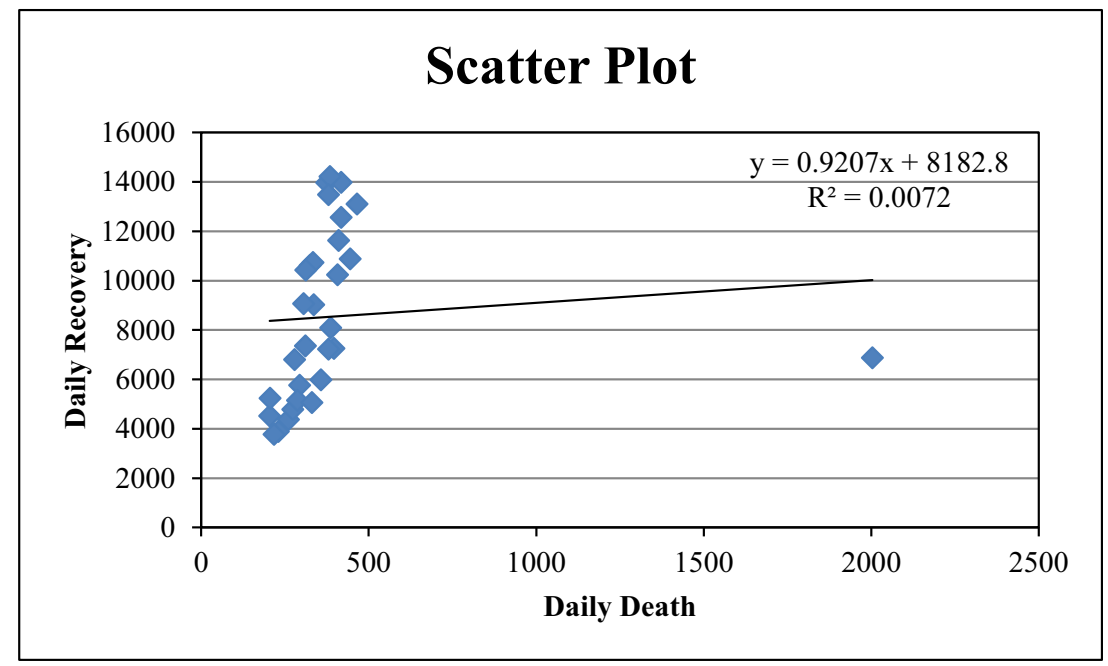


Presently, the number of people who have recovered from COVID-19 continues to increase. Worldwide, people, governments, health workers and doctors are struggling with this virus.

In India, the situation is similar to the rest of the world. India reported its first COVID-19 case on 30 January 2020, and the conditions have changed since the preliminary phase. The affected statistics have progressively increased, and the government is trying to reduce them. Central and state governments are working together to combat this worldwide pandemic. The government implemented 'Janta curfew', five phases of lockdown and the first unlock phase. The number of infected increased, and gradually, the number of recovered improved. The economy of India has been very much affected by this situation. Some industries are facing a huge amount of financial degradation. The GDP has decreased gradually, and it is at its lowest. The situation depends on the common people, the Government cannot stop this pandemic through their policy or other related information until the people are cautious about the pandemic and practice social distancing. Nevertheless, the recovery rate is very high in India. If people take some initial steps to reduce their chances of infection, it can have wonderful results in the future, and we shall break the chains of the coronavirus pandemic.

Acknowledgements We would like to thank the Vidyasagar University for supporting this research. We also express our gratitude to the Government of India for providing the necessary data to carry out this research. We also thankful to World Health Organization (WHO) for providing free worldwide COVID-19 data.

Authors contribution Bijay Halder: conceptualization, data analysis, software, writing - original draft, validation; Jatisankar Bandyopadhyay: supervision, investigation, writing - review and editing. Papiya Banik: data analysis, writing - draft, validation.

Role of funding source There is no funding source for this study.

Availability of data and materials All the data and materials are available at World Health Organization (WHO), Health, Ministry of India and Worldometer websites.

\section{Declarations}

Ethical approval This work does not involve personal data. This is a review of published data and literature. This study is based on World
Health Organization (WHO), Health, Ministry of India and Worldometer COVID-19 data and literature review. Also, all data is available at their provided websites. This manuscript has not been published, accepted for publication or under review for publication elsewhere.

Conflict of interest The authors declare that they have no conflict of interest.

\section{References}

Allocati N, Petrucci AG, Di Giovanni P, Masulli M, Di Ilio C, De Laurenzi V (2016) Bat-man disease transmission: zoonotic pathogens from wildlife reservoirs to human populations. Cell Death Discov 2(1):1-8. https://www.nature.com/articles/ cddiscovery 201648

Chakraborty I, Maity P (2020) COVID-19 outbreak: migration, effects on society, global environment and prevention. Sci Total Environ 728: 138882. https://doi.org/10.1016/j.scitotenv.2020.138882

Fan Y, Cheng X, Xue G, Wu J, Huang Z (2019) On the combination of luminescent rare earth MOF and rhodamine dopant with two sensing channels for picric acid. Spectrochimica Acta Part A: Mol Biomol Spectros 213:210-217. https://doi.org/10.1016/j.saa.2019.01.037

Hamzelou J (2020). World in lockdown. New Sci. 245:7. https://doi.org/ $10.1016 / \mathrm{S} 0262-4079(20) 30611-4$

Republicworld.com (2020), 31 May 2020: https://www.republicworld. com/india-news/politics/amit-shah-reveals-reason-for-unlock-1says-army-of-covid-warriors.html

Song HD, Tu CC, Zhang GW, Wang SY, Zheng K, Lei LC, Zheng HJ (2005) Cross-host evolution of severe acute respiratory syndrome coronavirus in palm civet and human. Proc Natl Acad Sci 102(7): 2430-2435. https://doi.org/10.1073/pnas.0409608102

Strains of Coronavirus, Webmd (2020) https://www.webmd.com/lung/ coronavirus-strains\#1

World Health Organisation report (2003) Summary of probable SARS cases with onset of illness from 1 November 2002 to 31 July 2003. Available Online: https://www.who.int/csr/sars/country/table2004_ $0421 / \mathrm{en} /$

World Health Organisation report (2013) Middle East respiratory syndrome coronavirus (MERS-CoV). Avalable online: https://www. who.int/emergencies/mers-cov/en/

World Health Organisation report (2020) Country and Technical guidance - Coronavirus disease (COVID-19). Available Online: https:// www.who.int/emergencies/diseases/novel-coronavirus-2019/ technical-guidance

Worldometer (2020) https://www.worldometers.info/coronavirus/?

Publisher's note Springer Nature remains neutral with regard to jurisdictional claims in published maps and institutional affiliations. 